\title{
Article \\ Abdominal Desmoid: Course, Severe Outcomes, and Unique Genetic Background in a Large Local Series
}

\author{
Gilad Ophir ${ }^{1, *,+}$, Shamai Sivan ${ }^{2,+}$, Strul Hana ${ }^{1}$, Rosner Guy ${ }^{1}$, Gluck Nathan ${ }^{1} \oplus$, Fliss Isakov Naomi ${ }^{1} \oplus$, \\ Klausner Joseph ${ }^{3}$, Wolf Ido ${ }^{2}$, Merimsky Ofer ${ }^{2}$, Goldberg Yael ${ }^{4}$, Levi Zohar ${ }^{5}$, Zer Alona ${ }^{6}$ and Kariv Revital ${ }^{1}$ \\ 1 Tel-Aviv Medical Center, Department of Gastroenterology and Hepatology, Sackler Faculty of Medicine, \\ Tel-Aviv University, Tel Aviv 6997801, Israel; hanas@tlvmc.gov.il (S.H.); guyr@tlvmc.gov.il (R.G.); \\ nathang@tlvmc.gov.il (G.N.); naomifl@tlvmc.gov.il (F.I.N.); revitalk@tlvmc.gov.il (K.R.) \\ 2 Tel-Aviv Medical Center, Institute of Oncology, Sackler Faculty of Medicine, Tel-Aviv University, \\ Tel Aviv 6997801, Israel; sivansh@tlvmc.gov.il (S.S.); idow@tlvmc.gov.il (W.I.); oferm@tlvmc.gov.il (M.O.) \\ 3 Tel-Aviv Medical Center, Department of Surgery, Sackler Faculty of Medicine, Tel-Aviv University, \\ Tel Aviv 6997801, Israel; Klausner.joseph@tlvmc.gov.il \\ 4 Rabin Medical Center, The Raphael Recanati Genetic Institute, Sackler Faculty of Medicine, \\ Tel-Aviv University, Tel Aviv 6997801, Israel; yaelgo43@clalit.org.il \\ 5 Rabin Medical Center, Department of Gastroenterology and Hepatology, Sackler Faculty of Medicine, \\ Tel-Aviv University, Tel Aviv 6997801, Israel; zoharl@clalit.org.il \\ 6 Rabin Medical Center, Institute of Oncology, Sackler Faculty of Medicine, Tel-Aviv University, \\ Tel Aviv 6997801, Israel; alonaz@clalit.org.il \\ * Correspondence: ophirg@tlvmc.gov.il; Tel.: +972-36974280 \\ + These authors contributed equally to this work.
}

check for
updates

Citation: Ophir, G.; Sivan, S.; Hana, S.; Guy, R.; Nathan, G.; Naomi, F.I.; Joseph, K.; Ido, W.; Ofer, M.; Yael, G.; et al. Abdominal Desmoid: Course, Severe Outcomes, and Unique Genetic Background in a Large Local Series. Cancers 2021, 13, 3673. https://doi.org/10.3390/ cancers 13153673

Academic Editors: Silvia Sanduleanu and Giovanni Crisafulli

Received: 13 June 2021

Accepted: 18 July 2021

Published: 22 July 2021

Publisher's Note: MDPI stays neutral with regard to jurisdictional claims in published maps and institutional affiliations.

Copyright: (c) 2021 by the authors. Licensee MDPI, Basel, Switzerland. This article is an open access article distributed under the terms and conditions of the Creative Commons Attribution (CC BY) license (https:/ / creativecommons.org/licenses/by/ $4.0 /)$.
Simple Summary: Abdominal desmoids are rare fibroblastic tumors. Though these tumors do not display metastatic potential, their locally aggressive nature can cause severe outcomes. Most cases appear sporadically, but 5-15\% are associated with familial adenomatous polyposis (FAP) syndrome. Current consensus recommendations do not offer a standard sequence of therapy due to the lack of data for some treatment options. Here, we present an ongoing clinical experience with abdominal desmoids. The majority of our patients suffered severe outcomes such as need for surgery or major tumor complications. A small, but unique group of 16 non-FAP mesenteric desmoid was found to harbor genetic alterations in cancer associated genes other than $A P C$, including CHEK2, BLM, ERCC5, MSH6, and PALB2.

Abstract: Introduction: Abdominal desmoid tumors are locally aggressive tumors that develop in familial adenomatous polyposis (FAP) patients, within the mesentery or abdominal wall. The understanding and implications of the treatment regimens are evolving. Aim: To assess the course, treatment, and outcomes of FAP and non-FAP abdominal desmoids and their related genetic alterations. Methods: Retrospective cohort study. Demographics, tumor characteristics, oncological and surgical history, complications, genetic-testing, and mortality data were retrieved from two tertiary referral centers. Results: Sixty-two patients were identified (46 FAP and 16 non-FAP). Thirty-eight patients $(61.3 \%)$ underwent surgical procedures (12 urgent and 26 elective). Out of 33 tumor resections, $39.4 \%$ recurred. Hormonal therapy, COX-inhibitors, chemotherapy, imatinib, and sorafenib were used in $35(56.4 \%), 30(48.4 \%), 18(29.1 \%), 7(11.3 \%)$, and $8(12.9 \%)$ of patients, respectively, with a 2 year progression-free survival of $67.8 \%, 57.7 \%, 38.4 \%$, and $28.5 \%$, respectively. Forty-one patients $(66.1 \%)$ suffered complications: bowel obstruction (30.6\%), hyperalimentation (14.5\%), ureteral obstruction $(12.9 \%)$, perforation $(11.3 \%)$, abscess formation (3.2\%), and spinal cord compression (3.2\%). Non-FAP patients carried pathogenic mutations in CHEK2, BLM, ERCC5, MSH6, and PALB2. Conclusions: Abdominal desmoids are mostly FAP-related and are associated with severe outcomes. We also report a group of non-FAP abdominal desmoids, which includes patients with additional cancer-related gene alterations. This interesting group should be further explored.

Keywords: desmoid tumor; familial adenomatous polyposis; next generation sequencing 


\section{Introduction}

Desmoid tumors are fibroblastic lesions thought to be associated with dysregulated wound healing. They can develop at any anatomic site, though the three dominant sites are extremities, abdominal wall, and intra-abdominal [1-3]. Initial presentation can be as asymptomatic masses, but progressive growth and infiltration of adjacent structures may cause symptoms, pressure, and ischemia, as well as obstruction of the internal organs [4-8]. Despite their locally aggressive nature, these tumors have no metastatic potential. Desmoid tumors are rare, with an incidence of about $2-5$ new cases per 1 million population per year $[1,2,9]$. Most cases appear sporadically, mainly at the trunk [10], but $5-15 \%$ are associated with familial adenomatous polyposis syndrome (FAP) [3,11], most of which are mesenteric and may present as multiple lesions [10].

Risk factors for desmoid, specifically abdominal, include high estrogen states such as pregnancy [12], and previous abdominal trauma or surgery [13,14]. As FAP patients account for only about $5-15 \%$ of all desmoid cases, a rare condition in itself, there are a paucity of data regarding this population and other heredities of this tumor. The natural history of desmoid tumors is unpredictable. Some patients experience spontaneous regression, some have stable disease for years, while others have a progressive disease that requires intervention [15]. Abdominal desmoids carry a higher risk for life threatening complications involving internal organs. FAP patients typically present with mesenteric desmoids that are more aggressive and multifocal than sporadic cases [10].

Several consensus meetings have recently attempted to standardize management, but did not address abdominal desmoids separately [1]. The latest consensus states that in asymptomatic patients, active surveillance is an acceptable strategy $[1,15,16]$. For symptomatic patients or those with progressively growing tumors, surgical resection is a viable option, especially for non-abdominal tumors, provided that the tumor presents in a favorable site not compromising the adjacent structures. Tumors that are unresectable, particularly mesenteric tumors in FAP patients, should be treated medically [17,18]. Medical options include a combination of hormonal anti-estrogen therapy with COX inhibitors [19], tyrosine kinase inhibitors (TKIs) [20,21], or chemotherapeutic regimens [22].

The current consensus recommendations do not offer a standard sequence of therapy because of a lack of data for some options. Thus, it has been recommended to consider the level of evidence, overall response rate, progression free survival (PFS), ease of administration, and expected toxicity of the administered drug, by following a five-dimensional model [1]. Typically, an initially less toxic treatment is followed by a more toxic one [1].

We present ongoing clinical experience with abdominal (mesenteric and abdominal wall) desmoids among FAP patients from two referral centers, as well as their course and response to treatment. We report a unique group of 16 non-FAP mesenteric desmoids, some with other cancers, and the associated findings of cancer related genetic alterations, thus suggesting additional molecular pathways related to this tumor.

\section{Methods}

This is a retrospective cohort study from two referral centers. Patients with a clinical and biopsy proven diagnosis of either mesenteric or abdominal wall desmoid tumor were identified from GI oncology, hereditary cancer, or soft-tissue tumors clinics. We included patients with an established FAP diagnosis and identified APC mutation. Additionally, we separately identified patients with mesenteric desmoids, in which APC testing did not reveal any pathogenic variants. Demographics, genetic workup, tumor characteristics collected from CT/MRI (initial and maximal size, number of tumors, and location), complications (i.e., bowel obstruction and perforation, ureter obstruction, GI bleeding, and need for total parenteral nutrition (TPN)), cancer history, surgical history, and mortality were documented. Medical therapy was recorded including COX inhibitors (celecoxib), hormonal therapy (tamoxifen), chemotherapy (either methotrexate and vinblastine or anthracycline-based), or TKI (imatinib or sorafenib). 
Treatment evaluation: Failure of treatment was defined as growth of tumor or development of tumoral complications necessitating a switch to another line of treatment. We defined specific treatment duration as time from the initiation of therapy to either treatment failure, death, or last follow up. The two year PFS rate was defined as the percentage of patients on a certain treatment regimen that did not progress for 2 years. A single physician in each medical center extracted data into a structured uniform database. All FAP patients were offered genetic workup by Sanger sequencing or next generation sequencing (NGS), or were tested for a known familial mutation. Patients with mesenteric desmoid and no known FAP-related phenotype or family history underwent endoscopic evaluation, and if polyps were found, underwent genetic evaluation as above. Some non-FAP cases underwent genetic consultation because of additional tumors and underwent a multi-gene NGS panel. All of the genetic tests were performed by medically certified laboratories.

\section{Statistical Analysis}

Continuous variables are presented as median + interquartile range (IQR), and dichotomous variables as proportions. Association between categorical variables was evaluated using Pearson's Chi-Square or Fisher's exact test. Mann-Whitney test was used to compare the distribution of continuous variables between the study groups. $p<0.05$ was considered statistically significant for all of the analyses. SPSS software was used for all of the analyses (IBM version 25, 2017. Armonk, NY, USA).

\section{Results}

\subsection{Patients and Desmoid Characteristics}

Sixty-two patients were identified: 46 FAP patients from 34 families, and 16 non-FAP patients. The median follow up time was 72.4 (IQR 37.1-151.9) months. Table 1 summarizes the baseline characteristics among all of the patients.

Table 1. Basic characteristics of the study population and complications among FAP and non-FAP groups.

\begin{tabular}{|c|c|c|c|c|}
\hline Parameter & FAP $(n=46)$ & Non-FAP $(n=16)$ & All $(n=62)$ & $p$ Value \\
\hline Sex-male $(\%)$ & $21(45.6)$ & $9(56.2)$ & $30(48.3)$ & 0.46 \\
\hline Median age at desmoid diagnosis (IQR) & $31(23-38)$ & $43.5(33-63.25)$ & $34(23-44)$ & 0.007 \\
\hline Median follow up, months (IQR) & $83.1(53.9-170.9)$ & $33.9(21.9-61.5)$ & $72.4(37.1-151.9)$ & 0.004 \\
\hline Median number of desmoids per patient (IQR) & $2(1-3)$ & $1(1-2.2)$ & $2(1-3)$ & 0.26 \\
\hline Median desmoid size at diagnosis, cm (IQR) & $4.7(3.5-7.6)$ & $8(4.2-13)$ & $5.5(3.5-8.8)$ & 0.08 \\
\hline Median maximal desmoid size, cm (IQR) & $7.9(4.5-10.7)$ & $8(5.4-14)$ & $8(4.7-11.5)$ & 0.76 \\
\hline \multicolumn{5}{|l|}{ Desmoid location } \\
\hline Abdominal wall (\%) & $4(8.7)$ & $1(6.25)$ & $5(8.1)$ & 0.13 \\
\hline Mesentery (\%) & $27(58.7)$ & $14(87.5)$ & $41(66.1)$ & 0.6 \\
\hline Both $(\%)$ & $15(32.6)$ & $1(6.25)$ & $16(25.8)$ & 0.08 \\
\hline Adverse events, patients (\%) & $31(67.3)$ & $10(62.5)$ & $41(66.1)$ & 0.72 \\
\hline Bowel perforation $(\%)$ & $5(10.8)$ & $2(12.5)$ & $7(11.3)$ & $>0.999$ \\
\hline Bowel obstruction (\%) & $16(34.7)$ & $3(18.7)$ & $19(30.6)$ & 0.34 \\
\hline Small bowel resection (\%) & $13(28.2)$ & $6(37.5)$ & $19(30.6)$ & 0.53 \\
\hline Ureter obstruction (\%) & $7(15.2)$ & $1(6.25)$ & $8(12.9)$ & 0.66 \\
\hline Ischemic colitis (\%) & $2(4.3)$ & 0 & $2(3.2)$ & $>0.999$ \\
\hline GI bleeding (\%) & $2(4.3)$ & 0 & $2(3.2)$ & 0.56 \\
\hline Need for TPN (\%) & $7(15.2)$ & $2(12.5)$ & $9(14.5)$ & $>0.999$ \\
\hline Abscess formation (\%) & $1(2.7)$ & $1(6.25)$ & $2(3.2)$ & $>0.999$ \\
\hline Spinal cord compression (\%) & $1(2.1)$ & $1(6.25)$ & $2(3.2)$ & 0.45 \\
\hline Surgery before appearance of desmoid (\%) & $42(91.3)$ & $1(6.25)$ & $43(69.3)$ & $<0.001$ \\
\hline $\begin{array}{l}\text { Pregnancy before appearance of desmoid } \\
\text { (\% of females) }\end{array}$ & $6(24)$ & $4(57.1)$ & $10(31.2)$ & 0.26 \\
\hline Death $(\%)$ & $2(4.3)$ & 0 & $2(3.2)$ & $>0.999$ \\
\hline
\end{tabular}


Most FAP patients (45/46) underwent bowel surgery before tumor appearance, compared with only one non-FAP patient $(6.25 \%)$, who underwent a right colectomy due to an advanced polyp. Ten female patients (31.2\% of females) were diagnosed during or after pregnancy, six of whom were FAP-associated. Only two FAP patients (4.3\%) received prophylactic therapy with celecoxib, as there is no official prophylaxis policy at either center.

\subsection{Genetic Findings}

Twenty-nine FAP patients (63.04\%) had a known pathogenic genetic variant in the APC gene. An additional seventeen patients were previously diagnosed with FAP, but did not have documentation of their genetic testing. Twenty-five of the FAP patients $(54.3 \%)$ had a clear history of desmoid tumors in their family. In 7 of 29 patients, the mutation was located between codon 1400 and the $3^{\prime}$ end of the APC gene. We found no correlation between the location of mutation and overall complications ( $23.5 \%$ of patients with mutations beyond codon 1400 suffered complications, compared with $20 \%$ with mutations closer to the $5^{\prime}$ end, $p>0.999$ ). Among the non-FAP patients, eight performed genetic workup, revealing four pathogenic variants and five variants of uncertain significance (VUS) (Table 2).

Table 2. Characteristics of non-FAP desmoid patients and their genetic alterations.

\begin{tabular}{|c|c|c|c|c|c|c|c|c|}
\hline $\begin{array}{l}\text { Patient } \\
\text { Number }\end{array}$ & Sex & $\begin{array}{c}\text { Age at } \\
\text { Diagnosis }\end{array}$ & $\begin{array}{l}\text { Desmoid } \\
\text { Location }\end{array}$ & Complications & $\begin{array}{l}\text { Other Ma- } \\
\text { lignancies }\end{array}$ & $\begin{array}{c}\text { Genetic } \\
\text { NGS } \\
\text { Panels } \\
\text { Performed }\end{array}$ & $\begin{array}{c}\text { Genes } \\
\text { with } \\
\text { Pathogenic } \\
\text { Variants }\end{array}$ & $\begin{array}{l}\text { Genes } \\
\text { with } \\
\text { VUS }\end{array}$ \\
\hline 1 & Male & 67 & Mesenteric & None & None & Yes & CHEK2 & $A P C$ \\
\hline 2 & Male & 29 & Mesenteric & None & $\begin{array}{l}\text { Germ cell } \\
\text { tumor }\end{array}$ & Yes & $\begin{array}{c}\text { ERCC5 } \\
B L M\end{array}$ & TP53 \\
\hline 3 & Male & 54 & Mesenteric & $\begin{array}{c}\text { Bowel perforation and } \\
\text { liver abscess }\end{array}$ & None & Yes & - & $B L M$ \\
\hline 4 & Female & 20 & Mesenteric & None & None & Yes & - & MSH2 \\
\hline 5 & Male & 69 & Mesenteric & $\begin{array}{l}\text { Bowel obstruction and } \\
\text { resection }\end{array}$ & $\mathrm{RCC}$ & Yes & - & CHEK2 \\
\hline 6 & Female & 38 & Mesenteric & None & None & Yes & MSH6 & - \\
\hline 7 & Male & 45 & Mesenteric & $\begin{array}{l}\text { Bowel obstruction and } \\
\text { need for TPN after } \\
\text { resection }\end{array}$ & None & Yes & PALB2 & - \\
\hline 8 & Male & 30 & Mesenteric & $\begin{array}{l}\text { Bowel and ureter } \\
\text { obstruction }\end{array}$ & $\mathrm{RCC}$ & Yes * & - & - \\
\hline 9 & Female & 37 & $\begin{array}{l}\text { Mesenteric } \\
\text { and } \\
\text { abdominal } \\
\text { wall }\end{array}$ & $\begin{array}{l}\text { Bowel perforation and } \\
\text { abscess formation }\end{array}$ & None & No & - & - \\
\hline 10 & Male & 62 & $\begin{array}{l}\text { Abdominal } \\
\text { wall }\end{array}$ & None & None & No & - & - \\
\hline 11 & Male & 68 & Mesenteric & Small bowel resection & None & No & - & - \\
\hline 12 & Female & 34 & Mesenteric & None & None & No & - & - \\
\hline 13 & Female & 81 & Mesenteric & None & $\mathrm{RCC}$ & No & - & - \\
\hline 14 & Male & 59 & Mesenteric & $\begin{array}{l}\text { Need for TPN after } \\
\text { resection }\end{array}$ & None & No & - & - \\
\hline 15 & Female & 42 & Mesenteric & Small Bowel resection & None & No & - & - \\
\hline 16 & Female & 9 & Mesenteric & $\begin{array}{l}\text { Sciatic nerve } \\
\text { involvement }\end{array}$ & None & No & - & - \\
\hline
\end{tabular}

NGS - next generation sequencing; VUS—variant of uncertain significance; * Patient 8 was found to carry an alteration in fumarate hydratase $(\mathrm{FH})$ gene, which was eventually deemed non-pathogenic. 


\subsection{Desmoid Related Morbidity}

A total of 39 patients (62.9\%) suffered significant complications, with a median of two events per patient (IQR 1-2). Table 1 summarizes these adverse events and their distribution between FAP and non-FAP patients. We found no correlation between maximal size or number of desmoid tumors and occurrence of complications $(p=0.28$ and 0.7 , respectively). Adverse events were not noted in any of the FAP-patients with only abdominal wall tumors.

\subsection{Surgical and Medical Treatment}

Thirty-eight patients $(61.3 \%)$ underwent abdominal surgery during follow up. Surgical procedures were divided into emergency procedures due to life threatening complications and elective procedures. Twelve patients (31.6\%) underwent emergency procedures-six due to small bowel perforation (one of the seven cases was considered a micro-perforation and was treated conservatively), five due to small bowel obstruction, and one patient due to uncontrolled gastrointestinal bleeding. Nine of these twelve patients were FAP-associated and three were non-FAP. Twenty-six of the 38 surgical patients (68.4\%) underwent elective desmoid resection-17 FAP associated and 9 non-FAP. Complete surgical resection was achieved in $33 / 38$ cases $(86.8 \%)$. Of these, 13 patients $(39.4 \%)$ had tumor recurrence, 3 after emergency surgery and 10 after elective resection. Ten patients with recurrence of the tumor were FAP associated $(76.9 \%)$ and three were non-FAP $(23.1 \%)$.

We found no correlation between the maximal size or number of desmoid tumors and need for surgery ( $p=0.88$ and 0.34 , respectively) for all types of surgery. Similar results were seen for elective and emergency surgeries, separately. We also noted no correlation between these parameters and risk for tumor recurrence ( $p=0.64$ and 0.47 , respectively).

Forty-six patients (41 FAP) were treated medically (Table 3 summarizes the prevalence, duration, and outcome per medication). Only five non-FAP patients received medical therapy (one had sorafenib and four had chemotherapy). Three had progressive disease requiring surgery, and the other two remained stable.

Table 3. Prevalence, duration, and outcome of the different treatment modalities.

\begin{tabular}{|c|c|c|c|c|c|c|c|}
\hline Therapy & $\begin{array}{c}\text { Patients } \\
\text { Treated as 1st } \\
\text { Line ( } \%)\end{array}$ & $\begin{array}{c}\text { Patients } \\
\text { Treated as 2nd } \\
\text { Line }(\%)\end{array}$ & $\begin{array}{c}\text { Patients } \\
\text { Treated as 3rd } \\
\text { Line }(\%)\end{array}$ & $\begin{array}{c}\text { Patients } \\
\text { Treated as } 4 \text { th } \\
\text { Line }(\%)\end{array}$ & $\begin{array}{c}\text { Treatment } \\
\text { Initiation, } \\
\text { Months from } \\
\text { Diagnosis, } \\
\text { Median (IQR) }\end{array}$ & $\begin{array}{l}\text { Treatment } \\
\text { Duration, } \\
\text { Months from } \\
\text { Initiation, } \\
\text { Median (IQR) }\end{array}$ & $\begin{array}{c}\text { Two Year } \\
\text { Progression } \\
\text { Free Survival } \\
(\%)\end{array}$ \\
\hline $\begin{array}{c}\text { COX } 2 \\
\text { inhibitors }\end{array}$ & $29(46.7)$ & 0 & $1(1.6)$ & 0 & $4.1(0-33.9)$ & $32.2(6.6-92.9)$ & 57.7 \\
\hline Hormonal & $33(53.2)$ & $1(1.6)$ & $1(1.6)$ & 0 & $9.1(0-48.7)$ & $44.1(7.1-103.7)$ & 67.8 \\
\hline Chemotherapy & $8(12.9)$ & 7 (11.2) & $3(4.8)$ & 0 & $16.8(5.1-49.5)$ & $17.7(7.9-23)$ & 38.4 \\
\hline Imatinib & $1(1.6)$ & $4(6.4)$ & $2(3.2)$ & 0 & $25.6(7.7-60.8)$ & $7.7(6.5-20.3)$ & 28.5 \\
\hline Sorafenib & $1(1.6)$ & $6(9.6)$ & $1(1.6)$ & $1(1.6)$ & $26.3(13.1-34.9)$ & $6.8(3.6-11.2)$ & $\mathrm{N} / \mathrm{A}$ \\
\hline
\end{tabular}

The two-year PFS is displayed in Figure 1. Only one patient on sorafenib therapy was treated for over 2 years; therefore, we looked at the median treatment duration (6.8 months), by which only $1 / 9$ (11.1\%) patients failed sorafenib therapy. COX inhibitors and hormonal therapy were initiated early after tumor diagnosis, at a median of 4.1 and 9.1 months, respectively. These drugs were used for the longest duration (median of 32.2 and 44.1 months, respectively). Table 3 and Figure 2 illustrate the initiation and duration of all medications. 


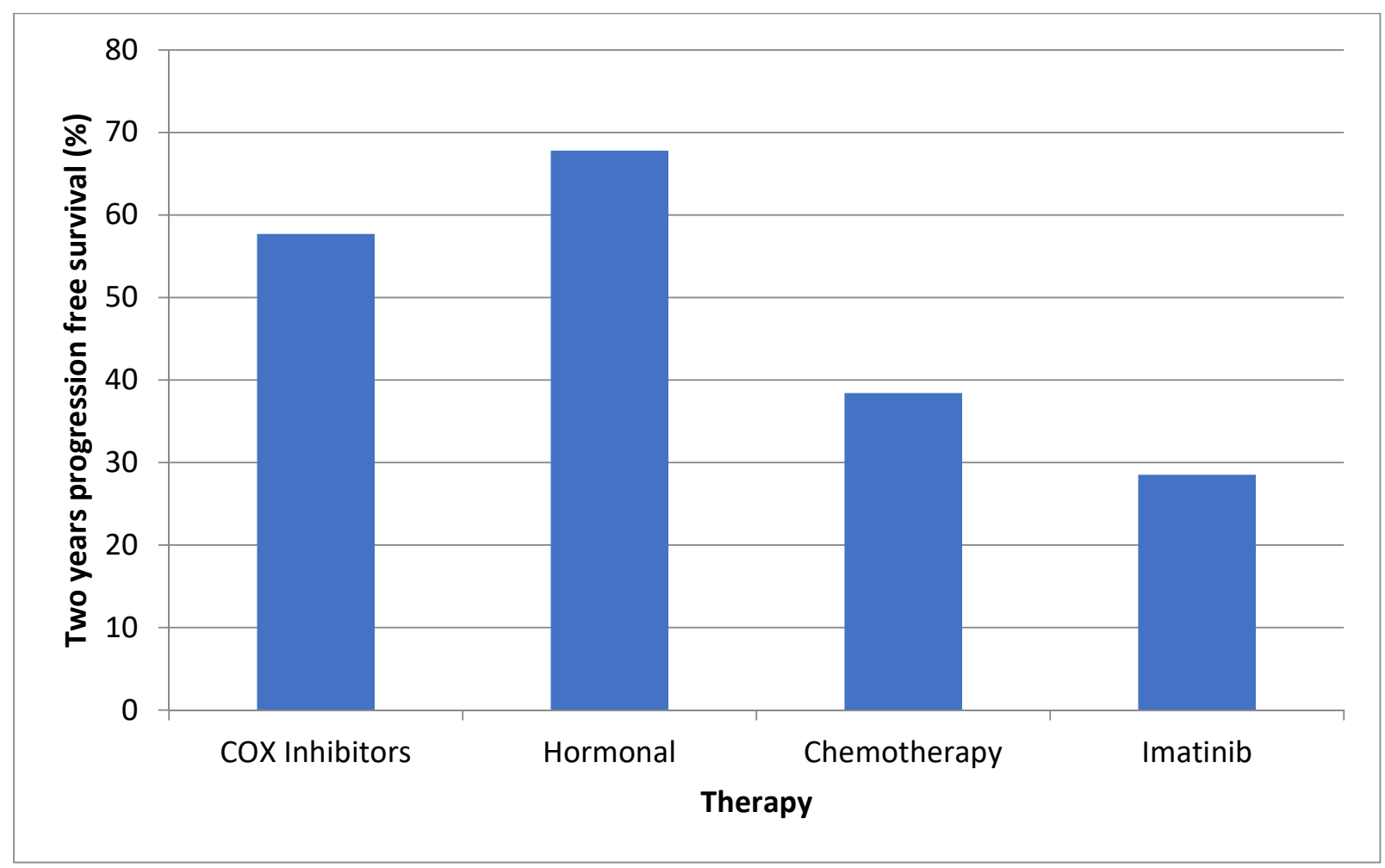

Figure 1. Two-year progression free survival according to different treatment modalities.

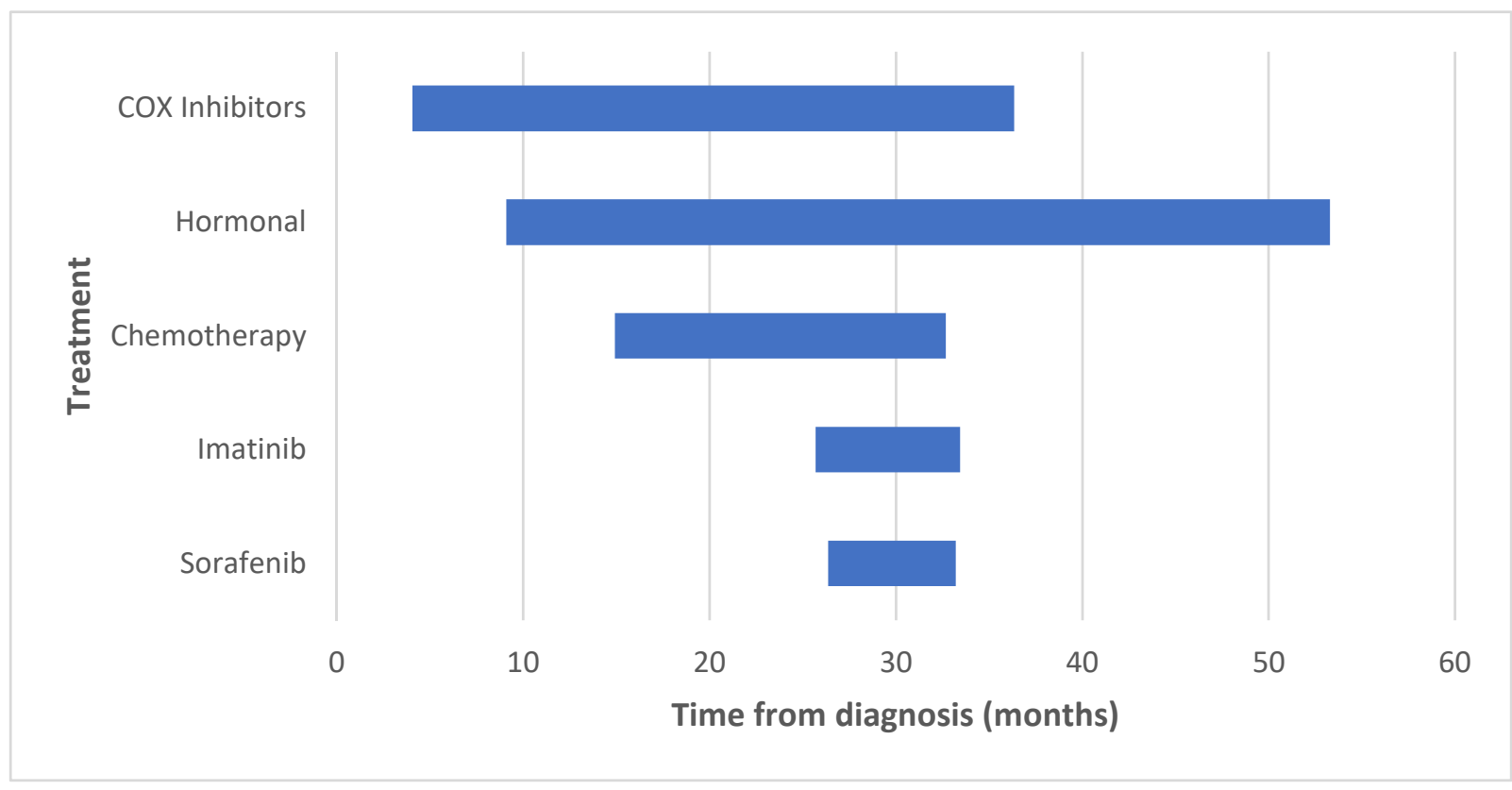

Figure 2. Initiation and duration of the various treatment modalities.

Sixteen patients (25.8\%) did not receive any medical treatment throughout follow-up: twelve had mesenteric tumors, one had an abdominal wall tumor and three had both. Eleven of the sixteen $(68.7 \%$ ) underwent surgical resection (nine elective and two urgent), five of whom relapsed. Five patients $(8.1 \%$ of the cohort) received neither medical nor surgical treatment, and were being monitored for disease progression. 


\subsection{Oncologic Outcomes and Mortality}

Of the 46 FAP patients, 18 (39.1\%) had other malignant or benign tumors during followup. Eleven patients $(23.9 \%)$ had osteomas or fibromas (Gardner syndrome), six (13.1\%) had papillary thyroid carcinoma, two had colorectal cancer (4.3\%), one had endometrial carcinoma, and one had a neuroendocrine tumor. Four non-FAP patients $(25 \%)$ had malignancies - three with renal cell carcinoma and one with germ cell tumor.

Two patients (3.2\%), both with FAP related desmoid, died during follow-up. One died due to progression of a neuroendocrine tumor. The other one had an abdominal desmoid with bilateral urethral obstructions requiring bilateral nephrostomies, and recurrent bowel obstructions requiring hyperalimenation with TPN. This patient had a prolonged hospitalization with recurrent bouts of urinary tract infections, and an invasive fungal infection attributed to her central venous catheter. She eventually succumbed to urosepsis.

\section{Discussion}

In this retrospective study of 62 patients with abdominal desmoid, mostly FAPassociated and with median follow-up of 6 years, we describe grave outcomes and complexity of clinical management. Sixty-three percent of our study population developed major, typically several complications. All complications were due to mesenteric desmoids causing mainly bowel obstruction (30.6\%), bowel perforation (11.3\%), and ureteral obstruction $(12.9 \%)$. Other studies report similar rates of bowel obstruction. Xhaja and Church described a rate of 35\% among 133 mesenteric FAP-associated desmoid patients, $69 \%$ of which required surgical intervention [4]. Soravia et al. reported slightly higher rate of $58 \%$ bowel obstruction and a $22 \%$ ureteral obstruction rate. However, a lower $2 \%$ perforation rate was reported among $53 \mathrm{FAP}$-associated desmoid patients [5]. Bowel perforation as a complication of desmoid tumors is mentioned in other studies only as case reports [6-8]. We reported two patients with neural involvement by desmoid tumor: one with spinal cord compression and another with sciatic nerve involvement. We found only one report with a similar case of a 12 year old girl who presented with a paraspinal sporadic desmoid with intra-spinous extension of the tumor causing scoliosis and paralysis [23]. Other case reports of paraspinal desmoid tumors appearing after spinal interventions [24] did not present with neurological deficits. Our cohort presented a high recurrence rate of $39.4 \%$ after surgical removal of the tumor. Other studies, which included mainly sporadic cases, demonstrated recurrence rates between $20-53 \%$ of cases [25-28]. Our data are in the highest range of recurrence rates in the literature, with the note that our population consisted mainly of FAP patients. While the burden of morbidity in our cohort was substantial, the mortality rate was surprisingly low-only two FAP patients ( $5 \%$ ) died during follow-up. Quintini et al. showed a significantly higher mortality rate of $22.1 \%$ in a cohort of 154 FAP patients over a similar follow up duration [29]. The lower mortality rate in our study might be attributed to dedicated desmoid clinics at both centers and to advanced therapeutic regimens that were introduced since Quintini's study, such as TKI therapy. Other studies show low mortality rates, however only a minority of abdominal desmoids were included $[19,30]$.

Assessing the efficacy of systemic therapy in desmoid tumors is complicated. These tumors can spontaneously regress in more than $25 \%$ of cases [16], and this might be mistaken as a response to therapy. Furthermore, mesenteric desmoids often appear as soft tissue infiltration in the mesentery, lacking the clear 3D look of a parenchymatic solid malignancy needed for Response Evaluation Criteria in Solid Tumors (RECIST). Abdominal imaging experts in our center felt that the RECIST criteria could not be applied accurately to all patients in our study. This is supported by a work from the French sarcoma group, where changes in MRI intensity signaling better predicted response to treatment when compared with the RECIST criteria [31]. We chose to use 2-year-progression free survival (PFS) to show the effect of therapy. This parameter was used by Gounder et al. in his trial on sorafenib in desmoid tumors [21]. We determined progression according to symptoms or MRI, and all patients were discussed in a multidisciplinary tumor board. 
Because of small numbers and the retrospective nature of this work, we were unable to directly compare various treatment modalities, as most patients were treated with either COX inhibitors and hormonal therapy or chemotherapy as first line therapy, and chemotherapy or TKIs as second line therapy. While COX inhibitors and hormonal therapy were started the earliest and lasted for the longest durations-approximately 3 and 4 years, respectively, these were utilized in asymptomatic patients who might have benefitted from close surveillance as well. There are no comparative trials to assess the efficacy of COX inhibitors in desmoid tumors, and regression reported in retrospective studies could represent the spontaneous regression that has been previously reported for desmoids [15]. Fiore et al. described a 2-year PFS of $89.6 \%$ among patients treated with toremifene [19]. Quast et al. reported similar results with sulindac and hormonal therapy, as $85 \%$ of patients showed regression or stabilization of the tumor [32]. However, a prospective study among 59 pediatric patients receiving tamoxifen and sulindac revealed less optimal results. The response rate was only $8 \%$ and the 2 -year PFS was only $36 \%$ [33].

The two-year PFS rates in our study were between $57-67 \%$ for these treatment groups, demonstrating a less optimal response than previous retrospective studies, but a much better response than that seen in the pediatric one [33]. The long duration of COX inhibitors and hormonal therapy in our cohort may support their role as a viable first-line therapy due to their moderate effectiveness and low related morbidity.

Published data regarding the efficacy of chemotherapy vary. Azzarelli et al. demonstrated a 5 years PFS of $67 \%$ using methotrexate and vinblastine [34]. Similarly, Palassini et al. demonstrated a 2-year PFS rate of about $80 \%$ using methotrexate and vinblastine [30]. This is in contrast with the results by Constantinidou et al., who showed a median time to progression of only 9 months using the same treatment regimen in 18 sporadic desmoid patients [22]. Our results are more similar to the latter study, with a 2-year PFS of about $40 \%$ and a median duration of therapy of only 18 months.

TKIs were often used as second- or third-line therapy. Our results with imatinib show a very low 2 years PFS of $28.5 \%$, which is considerably low compared with the available data. Chugh et al. enrolled 51 desmoid patients for imatinib therapy, and demonstrated 1 and 3 years PFS of 66 and 58\%, respectively [20]. Penel et al. described a 2-year PFS of $55 \%$ [35], and Kasper et al. showed progression arrest rate of $45 \%$ at 2 years [36]. These studies consisted mainly of sporadic desmoid patients.

It is premature to discuss our results regarding sorafenib, as only three patients hadbeen using it for more than 1 year. However, we report that with a median follow up of 6.8 months, only 11.1\% (1/9) had a documented progression. A large double-blind case-control study of 87 desmoid patients described similar results of a 2 -year PFS of $81 \%$ in the sorafenib group compared with $36 \%$ in the placebo group. The Kaplan-Meier curve showed a 9-month PFS of about 90\% [21].

We describe patients with non-FAP associated mesenteric desmoids carrying cancerpredisposing genetic variants. Half of these patients, who underwent NGS multigene panels, were found to carry a pathogenic variant, and another $37.5 \%$ had a variant of unknown significance. Alterations in CHEK2, a tumor suppressor gene, were discovered in two patients. CHEK2 is associated with Li-Fraumeni syndrome, an autosomal dominant disorder that manifests as multiple malignancies, including soft tissue sarcomas and breast cancer, supporting causality [37]. Other data have disproven this association [38]. Additional alterations were found in $B L M$, responsible for Bloom syndrome, an autosomal recessive disease associated with a wide range of malignancies (notably carcinomas, hematologic malignancies, and sarcomas) [39]. Three subjects were surprisingly found to carry genetic alterations associated with well-established genetic syndromes not usually related to desmoid tumors: two Lynch syndrome patients carried MSH6 mutation and VUS in $M S H 2$ and one patient had a mutation in PALB2, which encodes a BRCA2 interacting protein that increases susceptibility to breast and pancreatic cancers [40]. Pathogenic variants in these genes may be associated with increased risk for desmoids, however this requires 
further study. We therefore suggest genetic consultation and testing also for non-FAP patients with mesenteric desmoids.

The limitations of our study include its retrospective nature; the lack of a standardized treatment algorithm for desmoid patients, lack of control group of patients on active surveillance only, and missing data for referred patients. Our study also lacks a histology of surgical specimens; hence, we cannot report if complete surgical excision of the tumor, proliferation parameters, or molecular profiles had an impact on the outcomes.

The study strengths lie in the relatively large FAP-cohort of this rare condition; detailed information from two major referral centers; and a novel subgroup of non-FAP cases, some with alterations in cancer related genes that have not been previously described. We tracked details of several pharmacologic treatment lines and could evaluate them over time.

\section{Conclusions}

Abdominal desmoid tumors, while non-metastatic in nature, are associated with severe clinical outcomes. Therapeutic approaches vary, and include medical and surgical options, but with limited real-life data regarding their effectiveness because of the rarity of the disease. Further prospective studies are required to evaluate the therapeutic response and molecular profiles of desmoid tumors. We present a small, but unique, group of nonFAP mesenteric desmoids, some with genetic alterations in cancer associated genes other than APC. Cases with abdominal desmoid and no polyps, especially with background of additional tumors, should be referred for genetic consultation and appropriate testing.

Author Contributions: G.O., S.S., and K.R.-planning of study, data collection and interpretation, and drafting of manuscript. S.H., R.G., G.N., F.I.N., K.J., W.I., M.O., G.Y., L.Z., and Z.A.—data analysis and critical revision of article. All authors have read and agreed to the published version of the manuscript.

Funding: This research received no external funding.

Institutional Review Board Statement: The study was approved by review boards at both medical centers. Tel Aviv Medical Center Helsinki Committee 0491-20. Rabin Medical Center Helsinki Committee 0161-17. Both follow the ethical code of the declaration of Helsinki.

Informed Consent Statement: As this was a retrospective analysis of the data obtained from the archives of our hospitals, no formal written informed consent was obtained from patients.

Data Availability Statement: The data presented in this study are available upon request from the corresponding author.

Conflicts of Interest: The authors declare no conflict of interest.

\section{References}

1. Alman, B.; Attia, S.; Baumgarten, C.; Benson, C.; Blay, J.-Y.; Bonvalot, S.; Breuing, J.; Cardona, K.; Casali, P.G.; van Coevorden, F.; et al. The management of desmoid tumours: A joint global consensus-based guideline approach for adult and paediatric patients. Eur. J. Cancer 2020, 127, 96-107. [CrossRef]

2. Reitamo, J.J.; Hayry, P.; Nykyri, E.; Saxen, E. The desmoid tumor. I. Incidence, sex-, age- and anatomical distribution in the Finnish population. Am. J. Clin. Pathol. 1982, 77, 665-673. [CrossRef]

3. Fallen, T.; Wilson, M.; Morlan, B.; Lindor, N.M. Desmoid tumors-A characterization of patients seen at Mayo Clinic 1976-1999. Fam. Cancer 2006, 5, 191-194. [CrossRef]

4. Xhaja, X.; Church, J. Small bowel obstruction in patients with familial adenomatous polyposis related desmoid disease. Colorectal Dis. 2013, 15, 1489-1492. [CrossRef]

5. Soravia, C.; Berk, T.; McLeod, R.S.; Cohen, Z. Desmoid disease in patients with familial adenomatous polyposis. Dis. Colon Rectum 2000, 43, 363-369. [CrossRef] [PubMed]

6. Li, W.; Zhou, Y.; Li, Q.; Tong, H.; Lu, W. Intestinal perforation during chemotherapeutic treatment of intra-abdominal desmoid tumor in patients with Gardner's syndrome: Report of two cases. World J. Surg. Oncol. 2016, 14, 178. [CrossRef] [PubMed]

7. Shah, M.; Azam, B. Case report of an intra-abdominal desmoid tumour presenting with bowel perforation. Mcgill J. Med. 2007, 10, 90-92. [PubMed]

8. Tsiaousis, P.; Christopoulous, P.; Iordanidou, I.; Atmatzidis, S.; Panagiotopoulou, K.; Psaraleksis, K.; Atmatzidis, K. An intraabdominal desmoid tumor presenting with bowel perforation. A case report. Surg. Chron. 2008, 13, 327-331. 
9. van Broekhoven, D.L.M.; Grünhagen, D.J.; den Bakker, M.A.; van Dalen, T.; Verhoef, C. Time Trends in the Incidence and Treatment of Extra-Abdominal and Abdominal Aggressive Fibromatosis: A Population-Based Study. Ann. Surg. Oncol. 2015, 22, 2817-2823. [CrossRef] [PubMed]

10. Koskenvuo, L.; Ristimaki, A.; Lepisto, A. Comparison of sporadic and FAP-associated desmoid-type fibromatoses. J. Surg. Oncol. 2017, 116, 716-721. [CrossRef]

11. Koskenvuo, L.; Peltomaki, P.; Renkonen-Sinisalo, L.; Gylling, A.; Nieminen, T.T.; Ristimaki, A.; Lepisto, A. Desmoid tumor patients carry an elevated risk of familial adenomatous polyposis. J. Surg. Oncol. 2016, 113, 209-212. [CrossRef]

12. Fiore, M.; Coppola, S.; Cannell, A.J.; Colombo, C.; Bertagnolli, M.M.; George, S.; Le Cesne, A.; Gladdy, R.A.; Casali, P.G.; Swallow, C.J.; et al. Desmoid-type fibromatosis and pregnancy: A multi-institutional analysis of recurrence and obstetric risk. Ann. Surg. 2014, 259, 973-978. [CrossRef] [PubMed]

13. Schlemmer, M. Desmoid tumors and deep fibromatoses. Hematol. Oncol. Clin. N. Am. 2005, 19, 565-571. [CrossRef] [PubMed]

14. Sinha, A.; Tekkis, P.P.; Gibbons, D.C.; Phillips, R.K.; Clark, S.K. Risk factors predicting desmoid occurrence in patients with familial adenomatous polyposis: A meta-analysis. Colorectal Dis. 2011, 13, 1222-1229. [CrossRef] [PubMed]

15. Burtenshaw, S.M.; Cannell, A.J.; McAlister, E.D.; Siddique, S.; Kandel, R.; Blackstein, M.E.; Swallow, C.J.; Gladdy, R.A. Toward Observation as First-line Management in Abdominal Desmoid Tumors. Ann. Surg. Oncol. 2016, 23, 2212-2219. [CrossRef] [PubMed]

16. Bonvalot, S.; Ternes, N.; Fiore, M.; Bitsakou, G.; Colombo, C.; Honore, C.; Marrari, A.; Le Cesne, A.; Perrone, F.; Dunant, A.; et al. Spontaneous regression of primary abdominal wall desmoid tumors: More common than previously thought. Ann. Surg. Oncol. 2013, 20, 4096-4102. [CrossRef] [PubMed]

17. Clark, S.K.; Neale, K.F.; Landgrebe, J.C.; Phillips, R.K. Desmoid tumours complicating familial adenomatous polyposis. Br. J. Surg. 1999, 86, 1185-1189. [CrossRef]

18. Rodriguez-Bigas, M.A.; Mahoney, M.C.; Karakousis, C.P.; Petrelli, N.J. Desmoid tumors in patients with familial adenomatous polyposis. Cancer 1994, 74, 1270-1274. [CrossRef]

19. Fiore, M.; Colombo, C.; Radaelli, S.; Callegaro, D.; Palassini, E.; Barisella, M.; Morosi, C.; Baldi, G.G.; Stacchiotti, S.; Casali, P.G.; et al. Hormonal manipulation with toremifene in sporadic desmoid-type fibromatosis. Eur. J. Cancer 2015, 51, $2800-2807$. [CrossRef]

20. Chugh, R.; Wathen, J.K.; Patel, S.R.; Maki, R.G.; Meyers, P.A.; Schuetze, S.M.; Priebat, D.A.; Thomas, D.G.; Jacobson, J.A.; Samuels, B.L.; et al. Efficacy of Imatinib in Aggressive Fibromatosis: Results of a Phase II Multicenter Sarcoma Alliance for Research through Collaboration (SARC) Trial. Clin. Cancer Res. 2010, 16, 4884-4891. [CrossRef]

21. Gounder, M.M.; Mahoney, M.R.; Van Tine, B.A.; Ravi, V.; Attia, S.; Deshpande, H.A.; Gupta, A.A.; Milhem, M.M.; Conry, R.M.; Movva, S.; et al. Sorafenib for Advanced and Refractory Desmoid Tumors. N. Engl. J. Med. 2018, 379, 2417-2428. [CrossRef]

22. Constantinidou, A.; Jones, R.L.; Scurr, M.; Al-Muderis, O.; Judson, I. Advanced aggressive fibromatosis: Effective palliation with chemotherapy. Acta Oncol. 2011, 50, 455-461. [CrossRef] [PubMed]

23. Shindle, M.K.; Khanna, A.J.; McCarthy, E.F.; O’Neill, P.J.; Sponseller, P.D. Desmoid Tumor of the Spinal Canal Causing Scoliosis and Paralysis. Spine 2002, 27, E304-E307. [CrossRef] [PubMed]

24. Puvanesarajah, V.; Lina, I.A.; Liauw, J.A.; Hsu, W.; Burger, P.C.; Witham, T.F. Desmoid Tumor Formation following Posterior Spinal Instrumentation Placement. Evid. Based. Spine. Care. J. 2013, 4, 137-142. [CrossRef]

25. Huang, K.; Fu, H.; Shi, Y.-Q.; Zhou, Y.; Du, C.-Y. Prognostic factors for extra-abdominal and abdominal wall desmoids: A 20-year experience at a single institution. J. Surg. Oncol. 2009, 100, 563-569. [CrossRef] [PubMed]

26. Ballo, M.T.; Zagars, G.K.; Pollack, A.; Pisters, P.W.; Pollack, R.A. Desmoid tumor: Prognostic factors and outcome after surgery, radiation therapy, or combined surgery and radiation therapy. J. Clin. Oncol. 1999, 17, 158-167. [CrossRef]

27. Salas, S.; Dufresne, A.; Bui, B.; Blay, J.-Y.; Terrier, P.; Ranchere-Vince, D.; Bonvalot, S.; Stoeckle, E.; Guillou, L.; Le Cesne, A.; et al. Prognostic Factors Influencing Progression-Free Survival Determined From a Series of Sporadic Desmoid Tumors: A Wait-and-See Policy According to Tumor Presentation. J. Clin. Oncol. 2011, 29, 3553-3558. [CrossRef] [PubMed]

28. Shido, Y.; Nishida, Y.; Nakashima, H.; Katagiri, H.; Sugiura, H.; Yamada, Y.; Ishiguro, N. Surgical treatment for local control of extremity and trunk desmoid tumors. Arch. Orthop. Trauma Surg. 2009, 129, 929-933. [CrossRef]

29. Quintini, C.; Ward, G.; Shatnawei, A.; Xhaja, X.; Hashimoto, K.; Steiger, E.; Hammel, J.; Diago Uso, T.; Burke, C.A.; Church, J.M. Mortality of intra-abdominal desmoid tumors in patients with familial adenomatous polyposis: A single center review of 154 patients. Ann. Surg. 2012, 255, 511-516. [CrossRef]

30. Palassini, E.; Frezza, A.M.; Mariani, L.; Lalli, L.; Colombo, C.; Fiore, M.; Messina, A.; Casale, A.; Morosi, C.; Collini, P.; et al. Longterm Efficacy of Methotrexate Plus Vinblastine/Vinorelbine in a Large Series of Patients Affected by Desmoid-Type Fibromatosis. Cancer J. 2017, 23, 86-91. [CrossRef]

31. Crombé, A.; Kind, M.; Ray-Coquard, I.; Isambert, N.; Chevreau, C.; André, T.; Lebbe, C.; Cesne, A.L.; Bompas, E.; PipernoNeumann, S.; et al. Progressive Desmoid Tumor: Radiomics Compared With Conventional Response Criteria for Predicting Progression During Systemic Therapy-A Multicenter Study by the French Sarcoma Group. AJR. Am. J. Roentgenol. 2020, 215, 1539-1548. [CrossRef] [PubMed]

32. Quast, D.R.; Schneider, R.; Burdzik, E.; Hoppe, S.; Möslein, G. Long-term outcome of sporadic and FAP-associated desmoid tumors treated with high-dose selective estrogen receptor modulators and sulindac: A single-center long-term observational study in 134 patients. Fam. Cancer 2016, 15, 31-40. [CrossRef] [PubMed] 
33. Skapek, S.X.; Anderson, J.R.; Hill, D.A.; Henry, D.; Spunt, S.L.; Meyer, W.; Kao, S.; Hoffer, F.A.; Grier, H.E.; Hawkins, D.S.; et al. Safety and efficacy of high-dose tamoxifen and sulindac for desmoid tumor in children: Results of a Children's Oncology Group (COG) Phase II Study. Pediatr. Blood Cancer 2013, 60, 1108-1112. [CrossRef]

34. Azzarelli, A.; Gronchi, A.; Bertulli, R.; Tesoro Tess, J.D.; Baratti, D.; Pennacchioli, E.; Dileo, P.; Rasponi, A.; Ferrari, A.; Pilotti, S.; et al. Low-dose chemotherapy with methotrexate and vinblastine for patients with advanced aggressive fibromatosis. Cancer 2001, 92, 1259-1264. [CrossRef]

35. Penel, N.; Le Cesne, A.; Bui, B.N.; Perol, D.; Brain, E.G.; Ray-Coquard, I.; Guillemet, C.; Chevreau, C.; Cupissol, D.; Chabaud, S.; et al. Imatinib for progressive and recurrent aggressive fibromatosis (desmoid tumors): An FNCLCC/French Sarcoma Group phase II trial with a long-term follow-up. Ann. Oncol. 2011, 22, 452-457. [CrossRef] [PubMed]

36. Kasper, B.; Gruenwald, V.; Reichardt, P.; Bauer, S.; Rauch, G.; Limprecht, R.; Sommer, M.; Dimitrakopoulou-Strauss, A.; Pilz, L.; Haller, F.; et al. Imatinib induces sustained progression arrest in RECIST progressive desmoid tumours: Final results of a phase II study of the German Interdisciplinary Sarcoma Group (GISG). Eur. J. Cancer 2017, 76, 60-67. [CrossRef]

37. Manoukian, S.; Peissel, B.; Frigerio, S.; Lecis, D.; Bartkova, J.; Roversi, G.; Radice, P.; Bartek, J.; Delia, D. Two new CHEK2 germ-line variants detected in breast cancer/sarcoma families negative for BRCA1, BRCA2, and TP53 gene mutations. Breast Cancer Res. Treat. 2011, 130, 207-215. [CrossRef]

38. Malkin, D. Li-fraumeni syndrome. Genes Cancer 2011, 2, 475-484. [CrossRef]

39. Cunniff, C.; Bassetti, J.A.; Ellis, N.A. Bloom's Syndrome: Clinical Spectrum, Molecular Pathogenesis, and Cancer Predisposition. Mol. Syndromol. 2017, 8, 4-23. [CrossRef]

40. Hanenberg, H.; Andreassen, P.R. PALB2 (partner and localizer of BRCA2). Atlas Genet. Cytogenet. Oncol. Haematol. 2018, 22, 484-490. [CrossRef] 